\title{
New Trends in Non-Woven Wet Wipes
}

\author{
Janmay Singh Hada
}

National Institute of Fashion Technology, Assistant Professor \& Centre Coordinator, Textile Design Department, Jodhpur, Rajasthan- 3420037

To Cite this Article

Janmay Singh Hada, "New Trends in Non-Woven Wet Wipes", International Journal for Modern Trends in Science and Technology, 6(9S): 89-96, 2020.

\section{Article Info}

Received on 25-August-2020, Revised on 08-September-2020, Accepted on 12-September-2020, Published on 18-September-2020.

\section{ABSTRACT}

The wet tissue or wipes is emerging trend and fast growing market in non-woven materials. In light of global pandemic Covid 19, increasing concern and consciousness for better hygiene and cleanliness, non-woven industry is geared the formation of new products and variants of wet wipes like disinfectant wet wipes. It offers numerous advantage and meet user requirement for personnel care like body wipes, baby wipes, cosmetic wet wipes, cleaning wipes for domestic and industrial, flushable wipes and different variants. The wet wipes provide safety and protection of superior level with cleaning and disinfecting property.

The present paper discusses aboutnew trends and key design aspects for wet wipes category like as used of fibers (Natural/advanced), physical characteristics (like as orientation, porosity, thickness, weight, durability), chemical compositions of preservatives and efficacy testing,manufacturing process, hygiene measures and markets for future innovations, such as accelerators. This paper also study about the factors governs for low performer of wet wipes commercially.

KEYWORDS: Wet wipes, formulation and classification, packaging, markets, Future development's.

\section{INTRODUCTION}

Historically, Clothing was designed for safeguarding the human beings from the nature like cold, rain and snow. However, in recent times clothing also become fashion statement reflecting wearer personality and the image that he or she wants to convey. As the industry expanded so have concerns about the impact of environment on human being [1].

Arthur Julius (1957) idea for create of Wet-Nap ${ }^{\circledR}$ (disposable wet napkin) is superior to the normal towel and soap method. In first evolutionary period (monolithic era) wipes are simple and made from pulp or paper or rayon by wet laid or dry laid method. In blend era, spun laced rayon/polyester wipes introduced [2].
The wet tissues market is anincreasing popular growing business. They are item of everyday use like cleansing tissues like moistened towelette, disinfecting wipes, toilet paper, baby wipes or hard surfacewipes other products such as lotion for sun protection and deodorants etc. It develops the market for household and industrial applications for cleaning, sanitizing and polishing $\left[3^{3}\right.$.

The main purpose of using the wipes is to clean the face, remove dirt, oil residue and makeup products from the skin. The cleansing performance or how effectively the wipes can clean makeup and dirt is a key component of this product category.

The key component of fabric that handle the feel of fabric material are hand or smoothness, thickness and stiffness for sensory evaluation. The tactile properties (the feel of the fabric material) as 
mentioned in table use for evaluation methods for tactile properties of fabrics.

\begin{tabular}{|l|l|l|}
\hline S.No. & Properties & $\begin{array}{l}\text { Key areasfor fabric and } \\
\text { paper }\end{array}$ \\
\hline 1. & $\begin{array}{l}\text { Tactile and } \\
\text { sound }\end{array}$ & $\begin{array}{l}\text { mechanical, geometrical, } \\
\text { moisture and thermal } \\
\text { characteristics }\end{array}$ \\
\hline 2. & Mechanical & $\begin{array}{l}\text { stress and strain, stiffness, } \\
\text { force to press }\end{array}$ \\
\hline 3. & Geometrical & $\begin{array}{l}\text { size, shape, orientation of } \\
\text { the particles, such as } \\
\text { fuzziness and grittiness }\end{array}$ \\
\hline 4. & Moisture & $\begin{array}{l}\text { the perception of water } \\
\text { and/oil from the product }\end{array}$ \\
\hline 5. & Thermal & $\begin{array}{l}\text { heat transfer, such as cool } \\
\text { or warm sensations }\end{array}$ \\
\hline
\end{tabular}

Table1: Hand feel properties of paper and fabric [4]

Wet Wipes are made of Non-woven cloths and saturated with a solution of cleansing agents. They are mostly used for cleaning and disinfecting. The wet tissue liquids are mostly aqueous, the cellulose is a good nutrient, the nonwoven is always moderately contaminated with microorganisms and thestoragetemperature is nearly optimal for microbial growth. All factors for microbial attack are fulfilled.

The topic of preservation is always significance to formulators and finished good marketer's. They are conscious about necessity to effectively preserve their products in order to ensure product safely and be compliance with legislation.Wet wipes preservation is complex problem due to packaging of the liquid phase. Usually high number of the preservatives are required to complete long term protection against fungal and anti-bacterial contamination. For domestic and industrial applications, traditional preservatives like methylchloroisothiazolinone

Methylisothiazolinone (MI), benzisothiazolinone (BIT), Benzisothiazolinone (BT) and blends with formedehyde donors are still widely used [5].

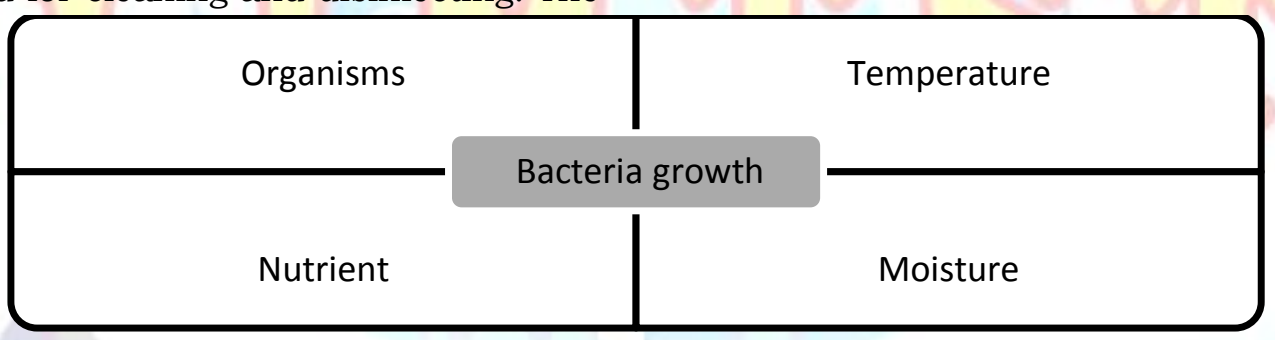

Figure 1 factors for microbial attack [6]

They are mainly used for disinfecting and cleansing the surface. Consumers want wipes soft and pleasant to the skin, light weight, no unpleasant odors and skin irritations, moisture absorption higher then cotton cool skin faster retain freshness to absorb, retain or release dust or liquid on demand. One of the main benefits that wipes provide is convenience - using a wipe is quicker and easier than the alternative of dispensing a liquid and using another cloth/paper towel to clean or remove the liquid. Most wipes are made of non-woven fabric similar to those used in dryer sheets. These are then saturated with a solution of water and gentle cleansing agents such as isopropyl alcohol. For that added scent, softness or moisturizing capability, the paper or cloth may also be treated with lotion and softeners.

To produce microbiological faultless wet tissues, an integrated microbiological quality management is necessary, consisting of raw material quality, production hygiene and a validated preservative system. The influence of the non-woven, the productionprocess, the choice of preservatives,preservative efficacy testing, responsiblecare and hygiene measures have to be taken into consideration [7].

\section{WET WIPES}

The main purpose of wet wipes is absorbing, retain, release dust or liquid. It allows to perform routine tasks in substantially less time for people. Some improved wet wipes include multiple layer of base sheet to provide a unique combination of properties which are not capable in single layer base sheet. In a layered base sheet include at least two layers of different physical properties of different fibres. One of the layer includes polyethylene fibers to provide gentle feel for skin while other layer of polypropylene provides strength and resiliency to withstand the exterior forces and maintain its stability and shape [8]. 
The Added scent, softness, moisturizing capability, disposable, cost and absorbency are the other factors which added value of wet wipes. The main structure of wet wipes composed form non-woven fabrics, cleansing ingredients.

\section{NON-WOVEN FABRIC}

$15 \%$ of all Non-woven used for making wet wipes [9]. Non-Woven Fabric used for creating baby wipes are generally non-woven fabrics made of polyester, polyethylene, cotton, rayon polypropylene as per end use of the wet wipes [10]. There are two primary methods of assembling non-woven fabrics are the wet laid and the dry laid process.

Dry laid process / melt blown: It is used to make non-woven fabrics from polymerresins. The polymer pellets are melted and then extruded through spinneret, by air fold manifold pressure. As the stream of fibers cools, it condenses to form a sheet. Godet rollers are used to flatten the fibers and bond them together.

Wet laid process: It is typically used for softer cloths, like diaper wipes like cellulose blends. The fibers are made into wet suspension with water and other chemicals. The resultant paste is pressed into flat sheets by rollers and then dried to form long rolls of fabric. These rolls are then further processed and slit into narrow widths and then perforated or cut into individual sheets. The finished cloths are classified by their dry weight that is at least $1.4 \mathrm{oz} / \mathrm{in} 2(40 \mathrm{~g} / \mathrm{m} 2)$. Absorbency of the wipes is also an important parameter like good quality wipes can absorb between $200 \%$ and $600 \%$ of their weight in solution.

Descriptive sensory analysis methods on fabric, paper, nonwoven products as well as DA methods on skin care lotions and cleansers have been published throughout the years. The terminology to describe hand-feel properties of paper and fabric based on previous work in this area as well as newly developed attributes generated from their research [11].

The cleansing ingredients usually consists of water, mild detergents, moisturizing agents, fragrance and preservatives. It contains with two portions a fabric carrier saturated with a liquor solution containing elements specific for the end use. The wipe holds, spreads the liquid or collects and holds dirt or other matter that is being removed. Fungal growth is often regarded as the main problem when preserving wet wipes as when it occurs it is highly visible and wet wipes are more susceptible to fungal growth than typical personal care or household products.

\section{FORMULATION OF WET WIPES}

The basic cleaning ingredient used for impregnating the wet wipes are basic (preservatives like potassium sorbate, 1,2 -Pentane diol Bronoplol) and auxiliary (moisturizers, surfactants, ph adjusters, anti-oxidants, emollients and solublizer). The water is main solvent used as a carrier and diluent for the other ingredients. The other the ingredients are added sequentially and mixed until homogenous. Generally, there are two systems like basic preservatives system and composite solution system. Basic system use for human body like cleansing wipes, hotels and baby wet wipes. Composite system includes auxillary agent with preservative system like as surfactant, anti-oxidants, nutritional elements etc. it is used for kitchens wipes, industrial wipes, make up removal wipes, pet wipes and wet wipes.

\begin{tabular}{|c|c|c|}
\hline S.No & Formula & Action \\
\hline 1. & $\begin{array}{l}\text { Preservatives: } \\
\text { Aqueous and } \\
\text { emulsion }\end{array}$ & $\begin{array}{l}\text { Protect from bacterial and } \\
\text { fungal infection (alcohol) }\end{array}$ \\
\hline 2. & $\begin{array}{l}\text { Surfactants: } \\
\text { surface active } \\
\text { agents }\end{array}$ & $\begin{array}{l}\text { Lower the surface tension } \\
\text { of water and facilitate easy } \\
\text { removal of dust and soil } \\
\text { particles. }\end{array}$ \\
\hline 3. & Emollients & $\begin{array}{l}\text { To keep the skin dry by } \\
\text { reducing water loss } \\
\text { through protective film on } \\
\text { skin }\end{array}$ \\
\hline 4. & Ph Adjuster's & $\begin{array}{l}\text { The Ph adjusters contain } \\
\text { such as citric acid or } \\
\text { sodium citrate, it } \\
\text { balanced the } \mathrm{Ph} 4-5 \text {. The } \\
\mathrm{PH} \text { is set around } 4.5-5.0 \\
\text { which is close to healthy } \\
\text { skin. }\end{array}$ \\
\hline 5. & Anti-oxidants & $\begin{array}{l}\text { It prevents oxidation of } \\
\text { oils (rancid smell) like } \\
\text { Vitamin E acetate }\end{array}$ \\
\hline 6. & Moisturizers & $\begin{array}{l}\text { It increases the water } \\
\text { content of skin and Keep } \\
\text { it soft like D-pantheol }\end{array}$ \\
\hline & Fragrances & $\begin{array}{l}\text { It makes from aroma } \\
\text { compound of volatile } \\
\text { chemicals which sense by } \\
\text { olfactory nerves in the } \\
\text { nose. }\end{array}$ \\
\hline
\end{tabular}

Table 2: Formulations of wet wipes [12].

However, testing has shown that wet wipes are just as susceptible to growth of bacteria but as 
bacterial contamination is usually not visible its presence goes unnoticed. The material is moistened with water or other liquids (e.g., isopropyl alcohol) depending on the applications. The material may be treated with softeners, lotions, or perfume to adjust the tactile andolfactory properties. Preservatives such as methylisothiazolinone are used to prevent bacterial or fungal growthin the package.

\begin{tabular}{|l|l|l|}
\hline S.No & Type & Name of formulation \\
\hline 1. & Organic acid & $\begin{array}{l}\text { Sorbic acid, benzoic } \\
\text { acid, de-hydro acetic } \\
\text { acid }\end{array}$ \\
\hline 2. & Alcohol & $\begin{array}{l}\text { Benzyl alcohol, phenoxy } \\
\text { ethanol }\end{array}$ \\
\hline 3. & Catatonics & $\begin{array}{l}\text { Poly amino propyl } \\
\text { bi-guanide }\end{array}$ \\
\hline 4. & $\begin{array}{l}\text { Multifunctional } \\
\text { additives }\end{array}$ & $\begin{array}{l}\text { Ethyl glycerine, glycol } \\
\text { like butylene glycol, } \\
\text { pentylene glycol etc. }\end{array}$ \\
\hline 5. & Chelating agents & $\begin{array}{l}\text { EDTA, Tetra sodium } \\
\text { glutamate diacetate }\end{array}$ \\
\hline
\end{tabular}

\section{Table 3: Chemical's used for preservatives in wet wipes}

The package should keep wipes moist, free from contamination and allow easy dispensing. Thermo-molded plastic containers are generally used. The design is the often-long term storage of partly used packs, evaporation of the solution, and the interaction between the various components of the wipes and packaging makes them more susceptible to contamination than most other personal care products.

The nature and composition of the wipe can have an effect on preservation/wipe interaction as well as subsequent preservative system performance. The thicker wet wipes are more absorbent, durable and use for heavy duty cleaning task. The use of natural fibers like aloe vera, oat mealoften providing more preservation difficulties.

\section{CLASSIFICATION OF WET WIPES AS PER APPLICATION}

\section{PERSONNEL CARE WIPES:}

The personnel care wet wipes maintain personnel and environmental hygiene standards for all users like as standard sealed cutlery package offered in restaurants or along with airline meals. It began to be marketed as a luxury alternative to toilet paper by 2005 by companies such as Kimberly-Clark and Procter \& Gamble.The wet wipes are a preferable option to the communal facilities, for which there are long queues.
Antibacterial wipes can help to sanitise restaurant tables, shopping trolleys, or swings in the playground to lower the exposure of germs. They also provide an easy way to maintain clean hands more effectively, especially when access to hand washing apparatus or even water is limited. Alcohol content can help reduce the spread of viruses, so schools are known to offer wet wipes to children for use on the way to lunch, or after trips to the washrooms

In Southeast Asia, wet wipes are often sold out of refrigerators to give the wipes a refreshingly cool effect.The intimate hygienic wipes, therefore, were 
made first and foremost to protect the woman's delicate intimate areas. The freshness and cleanliness are added bonus, feminine hygiene wipes are a newer entrant to the market their benefits for improved quality of life are already well recognized by women who use them for hygiene and convenience.

\section{BABY CARE:}

They are marketed for the long time due to widespread uses. They are designed to be handy, portable and hygiene to keep babies clean, yet still be disposable to cleanse the infants sensitive skin. The fabric is chosen on the basis of durability, cost and absorbency. it saturated with a cleansing a solution of gentle cleansing ingredientsaimed to be mild yet effective. These cloths are made from non-woven fabrics similar to those used in dryer sheets. They are typically sold in plastic tubs that keep the cloths moist and allow for easy dispensing[13].

It is preferred that baby wipes are formulated with a very sizableproportion of water. Water is the main ingredient and serves as a carrier and diluent for the other ingredients. However, water alone is not enough to effectively remove water-insoluble residues from feces and prevent the growth of microorganisms or maintain a healthy skin $\mathrm{PH}$.

Baby wipes also contain mild detergents mixed with moisturizing agents, fragrance, and preservatives. The detergents most commonly used are known as amphoteric surfactants, similar to those found in baby shampoos. Sodium di ampho acetate and coco phosphatidyl PG-diamonium chloride are primary surfactants used in wipes [14].

These chemicals do not shred the skin of natural oils and also decrease skin irritation potential. Mildness is a prime consideration given that the wipe solution may be in contact with delicate skin around the anus and genitals.Humectants such as propylene glycol and glycerine are added to prevent premature drying of the solution and contribute to skin moisturization.

In addition, some formulas incorporate oils such as mineral oil, lanolin, or silicones that help to soften skin. Thickeners, such as cellulose derivatives like hydroxymethyl cellulose, control the viscosity of the finished product and keep it the right consistency.

Other ingredients include preservatives, such as methyl and propyl paraben, to ensure the solution does not support microbial growth. Fragrance is usually added to increase consumer appeal and to help over-come body odours, but fragrance-free products are also offered. Featured ingredients that are known to be kind to the skin such as aloe vera or oatmeal extract.

\section{FACIAL AND COSMETIC WIPES:}

The facial cosmetic wipes category is faced to ascertain novel approaches and modify to the changing consumer needs and the evolving competitive landscape as makeup chemistries become more long-wearing, waterproof and hard to remove. Skin perception related to attributes can be leveraged from the work done on other skin care products [15].

These wipes are consisting of a nonwoven fabric material and a liquid part, which is also known as "juice" or solution of typically water, ethanol- or oil-based, and $90 \%-98 \%$ of the liquid is water in the wipes. The recipe of the liquid for makeup remover wipes are similar to other wet wipes, which includes an emollient to improve the glide of the wipe on the skin and to hydrate the residues to reduce dryness and irritation; a surfactant and/or an emulsifier to emulsify the emollient or any other water insoluble oils present in the composition with the function of breaking down the dirt, oil, or chemicals in the makeup products; a rheology modifier to increase the viscosity of the composition at lower temperatures as well as at process temperatures; a preservative to reduce the growth of microorganisms and to enable a longer shelf life; and a soothing agent to reduce the irritation or stinging/burning/itching effect of chemicals $[16,17]$.

Separate from the fabric properties, skin perception is another key component for wet wipe evaluation. Skin perception related attributes can be leveraged from the work done on other skin care products, such as lotion, cleanser, etc. Lexicon and descriptive analysis work have been widely studied. Meilgaard et al.listed the example of facial wipes skin-feel appearance and texture lexicon, which captured in-use, rinse/wet skin, and after-feel/dry skin perception related attributes [18]. 
The fibre sponge soaked with water, alcohol and other active ingredients for specific use. It uses for preventing infections, usually saturated with alcohol and bundled in sterile package. Hands and instrument may be disinfected with these pads while treating with wounds. It also used in first aid kit box.Example of surface cleaning pads including cosmetic wet wipes for make-up removal, anti-ageing wipes, anti-acne wipes, nail removal wipes, anti-spot treatments, anti-acne pads, vitamins, methanol and other treatments.

\section{INDUSTRIAL WIPES:}

Wet wipes also used for cleaning the industrial environments. In some industrial wipesare impregnated with solvent and chemicals to cleanse the surface. Industrial wet wipes made by spun lace technology which is strong and bio degradable material design to release the pre-moistened chemical's as per necessity. They are used in construction and automotive industries. The wet floor cares wipes are expected to get rapid gains.

\section{QUALITY CONTROL}

Each component used in wet wipes must pass a series of quality check points during the manufacturing process. The plastic packaging must be free from mild defects that could cause leakage or improper closure. The non-woven fabric must be uniformly formed and must meet specific tear-strength requirements. Furthermore, prior to manufacture, the cleansing solution must be thoroughly tested.

Development chemists evaluate the product to ensure that it is shelf stable and will not undergo any undesirable chemical reactions. They must also test the formula to ensure that it satisfies the requirements for mildness.

The most reliable method used to test mildness is known as the Human Repeat Insult Patch Test (HRIPT). In this test an ingredient, or series of ingredients, is applied to human volunteers (usually on the inside of the forearm). The area is then occluded with a patch material and the spot is evaluated by dermatologists or clinicians after a specified time. Any redness or irritation is assigned numerical value and the scores of all the panellists are averaged. A low average score, such as 0 or 1 , indicates that the product is essentially non-irritating.

\begin{tabular}{|l|l|l|}
\hline S.no & Place & Remarks \\
\hline 1. & Europe & $\begin{array}{l}\text { EU cosmetic directives new } \\
\text { cosmetic product regulation, } \\
\text { guidelines for good } \\
\text { manufacturing practice of } \\
\text { cosmetic products (GMPC) }\end{array}$ \\
\hline 2. & USA & $\begin{array}{l}\text { Cosmetic ingredient review (CIR } \\
\text { database) }\end{array}$ \\
\hline 3. & $\begin{array}{l}\text { South } \\
\text { east } \\
\text { Asia }\end{array}$ & ASEAN countries directives \\
\hline 4. & Japan & Standards for cosmetics \\
\hline
\end{tabular}

Table 4: Regulation of wet wipes worldwide

\section{PACKAGING:}

Packaging is an also important design component for pre-moistened wet wipes. These wipes folded inside the packets and dispenses as single sheets while keeping the towelettes moist until ready for use. Thermo-formed plastic tubs, large packet refills most commonly used to package wipes in different amounts ranging from a few dozen to several hundred.Large-pack refills, handy dispensers and attractive graphic labels are some of the recent innovations in the category. The finished product is then folded and placed inside packets, boxes or handy dispensers.

Packaging used in baby wipes must keep the cloths free from contamination, yet allow for easy dispensing. The package must also prevent the towelettes from drying out. Thermo-moulded plastic tubs are the packaging choice for most manufacturers. One common design features a hinged lid that allows easy access to the towelettes.

The good quality wipes are marketed as thicker, more absorbent, greater stretch ability, hypo-allergenic, alcohol-free, $\mathrm{pH}$-balanced, and/or unscented. Another factor that has impacted wipe design is the trend toward natural products. Marketers routinely add a variety of natural ingredients, such as aloe-vera and oatmeal, to increase the consumer appeal of their products.

\section{MARKET AND FUTURE DEVELOPMENTS}

The compound annual growth rate of wet wipes is about $7 \%$. Due to COVID 19 Pandemic, people more concern about hygiene product's. The baby wet wipes contain $50 \%$ market of wet wipes followed by Facial and cosmetic wipes, Hand and body wipes, Flushable wipes and Others like Floor cleaning etc. [19] 
The market trend is leaning toward larger, more economical size. For example, Huggies recently introduced a 160-count refill package. Smaller travel size packages are also available from some manufacturers. From a technical perspective, as chemists develop new and improved surfactants, future versions of baby wipes will contain milder and more effective cleansing ingredients. Trends in fragrance and featured ingredients will also impact future formulations. They are wet wipes use to cleanse the sensitive sins of infantssaturated with gentle cleaning ingredients to alcohol base cleaners, sold in plastic tubes, keep the cloth moist, allow for easy for dispensing.

Chicopee/Avintiv is in the process of developing a global line of industrial general purpose wipes using its Spun lace nonwovens technology. Spun lace, a proprietary technology developed by Avintiv, gives users all of the performance attribute like low lint, absorbency, and a clean surface preferred in wiping.More recently, Chicopee developed a new dispensing system to allow users to create tailor-made, single-use wet wipes.The Michigan-based company Hyge announced the development of its biodegradable wet wipes on a roll.

Biossance has developed an advanced product called Squalane and anti-oxidant cleansing Cloths. These kinds of alcohol-free and biodegradable products are intended to remove long wear makeup, condition lashes and brows, and hydrate skin easily for feminine hygiene market.

It is worth considering the flushable wet wipes, when flushed down the toilet, have been known to clog internal plumbing, septicsystems and public sewer systems. The tendency for fat and wet wipes to cling together encourages the growth of theproblematic obstructions in sewers known as "fat bergs". In addition, some brands of wipes contain alcohol, which can kill the bacteria and enzymes responsible for breaking down solid waste in septic tanks. The main technology behind flushable wet wipes are wet webs by mechanical hydro entanglement which produce more uniformity then spun lace fiber blend of wood pulp and cellulosic fibers [20].

For pet care wipes have also entered the market, such as Pawtizer, an antibacterial paw wipe because there are as many germs on paws as on human hands[21].

\section{CONCLUSION}

The landscape overview of the wet wipes products applied to all segments from the global market to different products category, how the products differentiate themselves from each other. This will guide the readers to understand the wet wipes products better in term of quality, category and future growth. It is important to include the cleaning performance attributes for the future wet wipes development. This uniqueness also differentiates wet wipe evaluation from non-woven fabric or cloth evaluation or lotion/liquid cleanser product categories.

\section{REFEENCES:}

1. Sustainability report (2019), pulp and fiber business, https://www.adityabirla.com/upload/pdf/Birla-Cellulose-SDR -2018-19.pdf.

2. Mango, P. (2005, August) Evolution of wet wipes-past, Present and Future, Research gate.

3. Sular, V.; Okur, A.E. (2007, January), Sensory evaluation methods for tactile properties of fabrics.

4. Civille, G.V.; Dus, C.A. (1990) Development of terminology to describe the hand feel properties of paper and fabrics. J. Sens. Stud., 5, pp. 19-32.

5. Siegert, W. (2011, May) Preservatives terns in wet wipes, Research Gate https, 232273400.

6.

https://www.personalcaremagazine.com/story/10272/the-pre servation-of-wet-wipes.

7. Gupta, A. (2020)Project Report on Wet Wipes Manufacturing, Engineered India research Institute, accessed on 21/08/2020.

8. https://patents.google.com/patent/US6028018A/en.

9. Zhang, D. (2010) Non-woven for consumer and industrial wet wipes, Application of non-woven in technical textiles, pp: 103-119.

10.https://www.technicaltextile.net/articles/ conversion-of-no nwoven-3509.

11.Civille, G.V.,Dus, C.A. (1990) Development of terminology to describe the hand feel properties of paper and fabrics. J. Sens. Stud. pp. 19-32.

12. https://www.Donggong wet wipes.

13.http://www.madehow.com/Volume-6/Baby-Wipes.html\#ix zz6Ho8qvRH4.

14.

https://onlinelibrary.wiley.com/doi/full/ 10.1111/pde. 14112. 15. Huajing, X., Krogmann, A.R., Claudette, V., Edgar, C.(2019, July 21) Understanding the global sensory landscape for facial cleaning/ make remove wipes, MDPI Journal, Cosmetics, Volume 6, Issue 3.

16. Russell, S.J. (2007) Handbook of Nonwovens; Woodhead Publishing Limited: Cambridge, UK.

17. Kaplan, S.; Pulan, S.; Ulusoy, S. (2017). Objective and subjective performance evaluations of wet wipes including herbal components. J. Ind. Text., pp. 1-20. 
18. Meilgaard, M.; Civille, G.V.; Carr, B.T. (2007) Sensory Evaluation Techniques, 4th ed.; CRC Pres: Boca Raton, FL, USA pp. 161-172.

19. Maida, J. (2020, July 19) Wet Tissue and Wipe Market Analysis Highlights the Impact of COVID-19, Technavio Research.

20. Wilson, A. (2018, July 15) Flushable wipes: a perfect technological contradiction, International fiber Journal. Accessed on 08/09/20.

21.https://www.nonwovens-industry.com/contents/view_brea king-news/2019-01-17/michigan-startup-launches-wet-wipeson-a-roll.

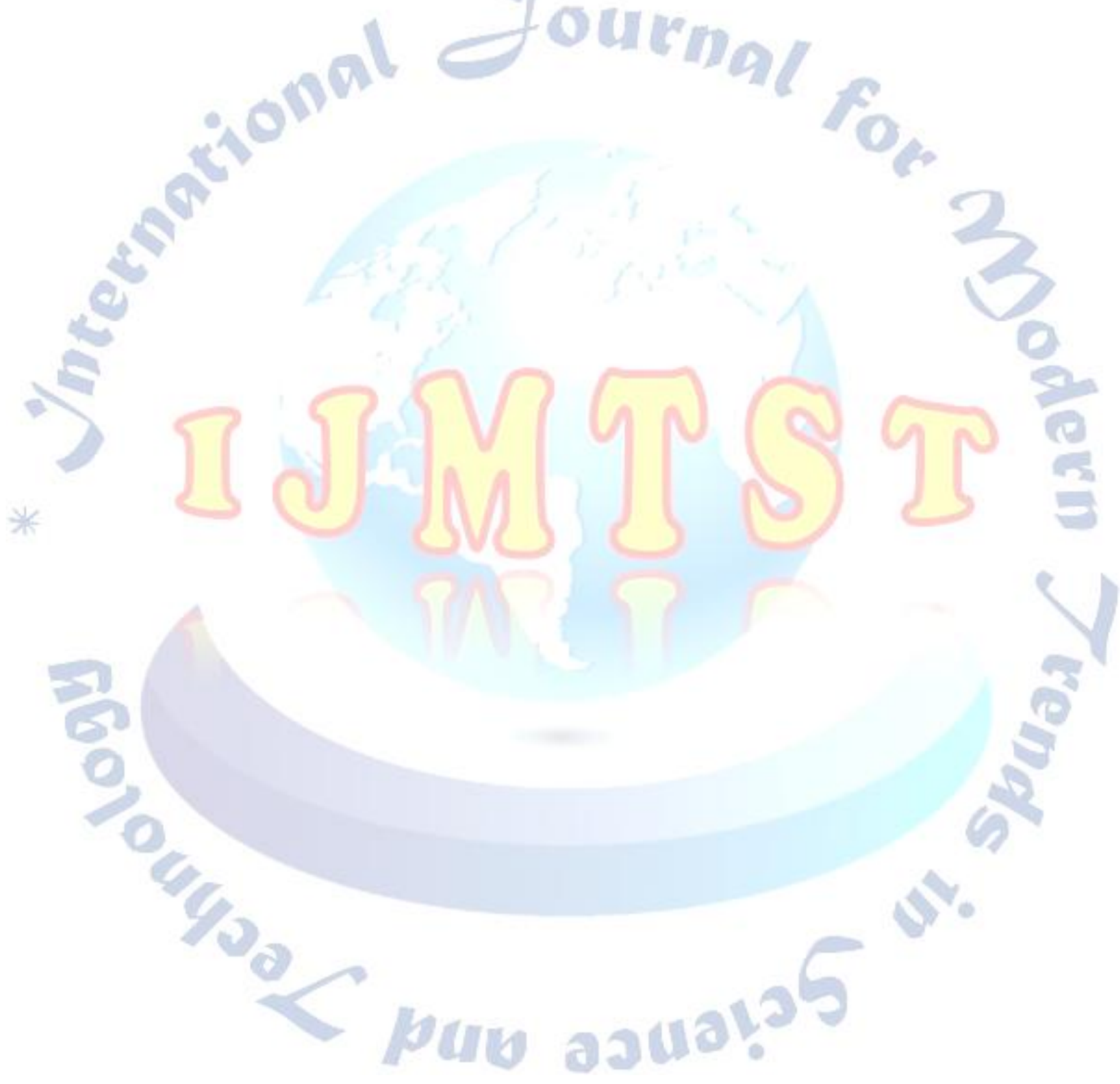

